\title{
Efficacy of thalidomide in a girl with inflammatory calcinosis, a severe complication of juvenile dermatomyositis
}

\author{
Takako Miyamae ${ }^{\prime *}$, Fumie Sano ${ }^{1}$, Remi Ozawa' ${ }^{1}$, Tomoyuki Imagawa', Yoshiaki Inayama², Shumpei Yokota ${ }^{1}$
}

\begin{abstract}
We report a 14-year-old girl with juvenile dermatomyositis (JDM) complicated by severe inflammatory calcinosis successfully treated with thalidomide. She was diagnosed as JDM when she was 4 years old after a few months of increasing lethargy, muscle pain, muscle weakness, and rash. During three months, clinical manifestations and abnormal laboratory findings were effectively treated with oral prednisolone. However, calcinosis was recognized 18 months after disease onset. Generalized calcinosis rapidly progressed with high fever, multiple skin/subcutaneous inflammatory lesions, and increased level of CRP. Fifty mg/day $(1.3 \mathrm{mg} / \mathrm{kg}$ day) of oral thalidomide was given for the first four weeks, and then the dose was increased to $75 \mathrm{mg} /$ day. Clinical manifestations subsided, and inflammatory markers had clearly improved. Frequent high fever and local severe pain with calcinosis were suppressed. The levels of FDP-E, IgG, and tryglyceride, which were all elevated before the thalidomide treatment, were gradually returned to the normal range. Over the 18 months of observation up to the present, she has had no inflammatory calcinosis, or needed any hospitalization, although established calcium deposits still remain. Her condition became painless, less extensive and less inflammatory with the CRP level below $3.08 \mathrm{mg} / \mathrm{dL}$. Recent examination by whole-body 18F-FDG-PET-CT over the 15 months of thalidomide treatment demonstrated fewer hot spots around the subcutaneous calcified lesions.
\end{abstract}

\section{Background}

Juvenile dermatomyositis (JDM) is a systemic connective tissue disease characterized by typical skin rash and chronic muscle inflammation of uncertain etiology [1]. Classic JDM presents with an insidious progression of malaise, easy fatigue, muscle weakness, fever, and rash that may predate diagnosis by three to six months. Calcinosis is one of the severe complications of JDM, and despite recent progress in the treatment of this disorder, it still occurs in up to $40 \%$ of patients [2,3]. The onset of calcinosis usually occurs one to three years after that of the illness.

Our understanding of the pathogenesis of calcinosis is still very limited. However, it has begun to come into focus through the following recent findings. The calcinosis itself is associated with inflammation. It has been reported that macrophages and proinflammatory

\footnotetext{
* Correspondence: tmiyamae@med.yokohama-cu.ac.jp

${ }^{1}$ Department of Pediatrics, Yokohama City University, 3-9 Fukuura,
} Kanazawaku, Yokohama 236-0004, Japan cytokines, such as IL-6, IL-1, and TNF-alpha, were present in the white, calcium-rich fluid (calcium milk) collected from a patient [4]. Moreover, calcinosis has been more frequently associated with TNF-alpha-308A promoter polymorphism, which is associated with increased TNF- alpha production by peripheral blood mononuclear cells [5].

The deposition of calcium, mostly in the skin, around the joints, and in the intermuscular fascial planes, may cause more long-term disability than the myositis itself. The relatively low incidence of calcinosis observed in recently reported case series suggests that earlier diagnosis and more aggressive treatment such as corticosteroid and immunosuppressant therapy are required [6]. However, once established, the disease is still difficult to treat.

Recently, the effectiveness of the monoclonal antibody to TNF-alpha, infliximab, in the treatment of refractory juvenile dermatomyositis with calcinosis has been reported [7]. In that study, calcinosis was still present in all five patients who received infliximab, but, notably, it 
became softer, painless and, in four cases, less widespread.

Thalidomide has been accepted as an immunomodulatory drug in refractory pediatric autoimmune diseases such as Behcet's disease and systemic onset juvenile idiopathic arthritis $[8,9]$. It has been demonstrated that thalidomide selectively inhibits the TNF-alpha and IL-6 mRNA expression in human peripheral blood mononuclear cells [10]. The inhibitory effect of thalidomide on monocyte TNF-alpha is thought to be the main mechanism of its action as an anti-inflammatory agent [11].

We report a case of severe calcinosis in a 14-year-old girl who was treated with thalidomide, a treatment encouraged by the partial effectiveness of etanercept, a soluble TNF receptor fusion protein.

\section{Case presentation}

The patient was a girl of 14 years of age, in whom JDM had been diagnosed in January 1998, when, at 4 years of age, she had been experiencing increasing lethargy, muscle pain, muscle weakness, and rash for a few months. Calcinosis had been recognized 18 months after the diagnosis was made (Fig. 1). For 3 months, clinical manifestations and abnormal laboratory findings were effectively treated with oral prednisolone. Her muscle weakness and elevated muscle-derived enzymes were normalized with this treatment, and the myositis was stable after that. However, generalized calcinosis progressed rapidly with high fever, multiple skin and subcutaneous inflammatory lesions, and an increased level of CRP. Examination of the subcutaneous calcium milk revealed markedly elevated levels of IL-6, TNF-alpha, and IL-1beta by ELISA (Fig 2). Methylprednisolone pulses, cyclophosphamide, cyclosporine, azathioprine, probenecid and magnesium hydroxide and aluminum hydroxide were administered, but these treatments failed, resulting in repeated rupture, drainage and resection at calcinosis sites (Fig 3). "Inflammatory calcinosis" events, defined as subcutaneous inflammation caused by calcification with one or more of the following, (1) pain (VAS $>50 \mathrm{~mm})$, (2) fever $\left(>38.0^{\circ} \mathrm{C}\right.$, and (3) an elevated level of CRP $(>5 \mathrm{mg} / \mathrm{dL}$ ), were not suppressed by the conventional treatments at all. As shown in Fig. 4, fusion imaging systems combining 18F-FDG PET (Fluorodeoxyglucose-Positron Emission Tomography) and CT visualized anatomical location of the hot spot lesions of inflammatory calcinosis. Pathological evaluation of this inflammatory calcinosis revealed calcium plaques with fibrinoid vasculitis, inflammatory cell infiltration, hemorrhage and degeneration of adipose cells. (Fig. 5)

Infliximab, the monoclonal antibody to TNF-alpha, was administered in 2003, when the patient was 9 years a.

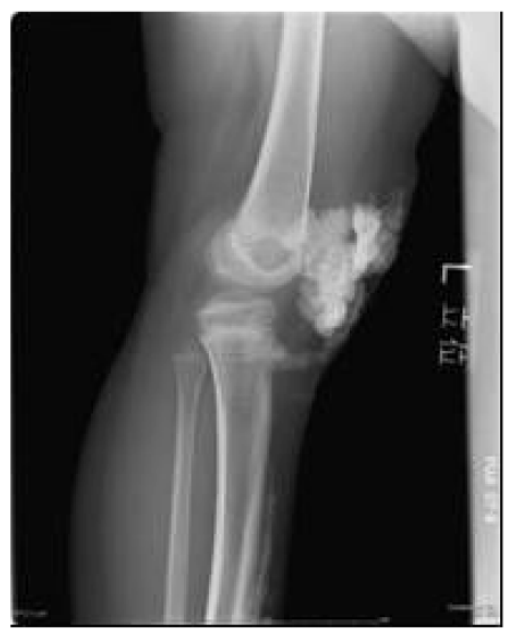

b.

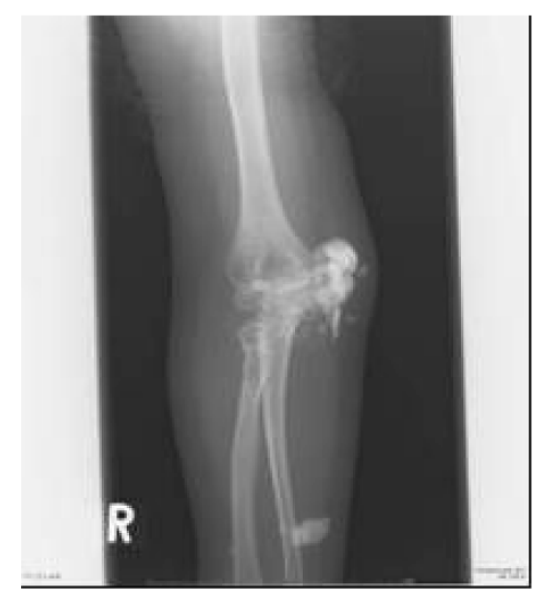

c.

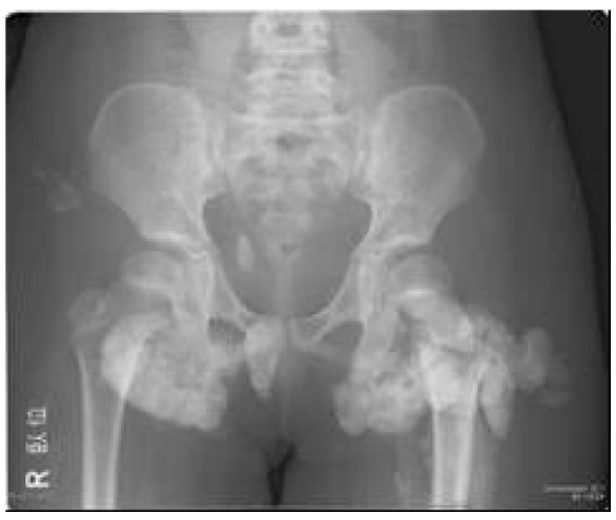

Figure $1 \mathrm{X}$-ray findings of extremities and pelvis. a. Calcium deposit around right knee in April 2001, 3 years and 3 months after JDM onset. b. Subcutaneous calcium nodule over right elbow in January 2003, 5 years after JDM onset. c. Tumoral calcinosis in the buttocks in September 2003, 5 years and 8 months after JDM onset. 


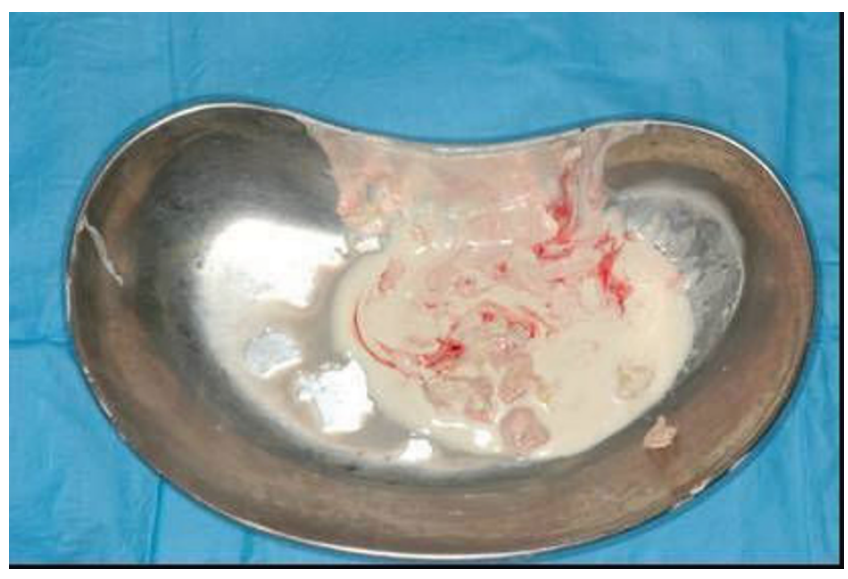

\begin{tabular}{|l|l|l|l|l|l|l|}
\hline & IL-12 p70 & TNF- $\alpha$ & IL-10 & IL-6 & IL-1 $\beta$ & IL-8 \\
\hline $\begin{array}{l}\text { Calcium fluid } \\
(\mathrm{pg} / \mathrm{mL})\end{array}$ & 6.6 & 63,148 & 460.9 & $1,090,669$ & 4.325 & 67,144 \\
\hline Serum $(\mathrm{pg} / \mathrm{mL})$ & 17.1 & 41.2 & 10.7 & 63.5 & 5 & 323.2 \\
\hline
\end{tabular}

Figure 2 Calcium milk drained with small amounts of calcium deposits from buttock (top). Characteristics of proinflammatory cytokines in serum and calcium milk. (bottom). Examination of subcutaneous calcium milk revealed highly elevated levels of IL-6, TNF- $\alpha$, and IL-1 $\beta$.

old, but it was discontinued due to adverse effects and replaced with etanercept. Being encouraged by the partial effectiveness of subcutaneous injection of $25 \mathrm{mg}(0.8$ $\mathrm{mg} / \mathrm{kg}$ ) of etanercept twice a week, her high fevers became less frequent. However, surgical approaches to the removal of the calcium deposits were still required because of inflammatory calcinosis with severe pain, rupture, or both at the calcinosis sites.

Etanercept treatment was replaced with thalidomide treatment in 2006 at the age of 12 after receiving approval from the ethical committee and informed consent from the patient and her parents. Fifty $\mathrm{mg} /$ day $(1.3$ $\mathrm{mg} / \mathrm{kg}$ day) of oral thalidomide (Sauramide ${ }^{\bullet}$ Penn
Pharmaceuticals, Tredegar, UK) was given for the first four weeks, and then the dose was increased to $75 \mathrm{mg} /$ day. Clinical manifestations subsided, and inflammatory markers had clearly improved (Table 1). Frequent high fever and local severe pain with calcinosis were suppressed. The levels of FDP-E, IgG, and tryglyceride, which were all elevated before the thalidomide treatment, were gradually returned to the normal range. Over the 18 months of observation up to the present, she has had no inflammatory calcinosis, or needed any hospitalization, although established calcium deposits still remain. Her condition became painless, less extensive and less inflammatory with the CRP level below

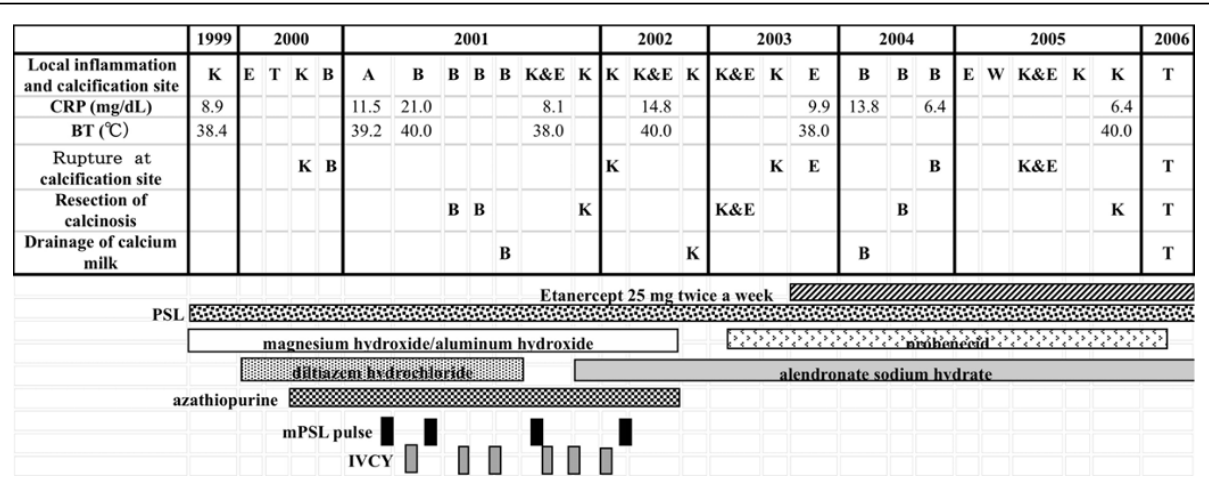

Figure 3 Clinical course of the patient and "inflammatory calcinosis" defined as subcutaneous inflammation caused by calcification with one or more of: (1) pain (VAS $>50 \mathrm{~mm}),(2)$ fever $\left(>38.0^{\circ}\right)$, and (3) elevated level of CRP (>5 mg/dL). K: knee, E: elbow, T: thigh, B: buttock, W: wrist, mPSL: methyl prednisolone; IVCY:intravenous cyclophosphamide pulse. 


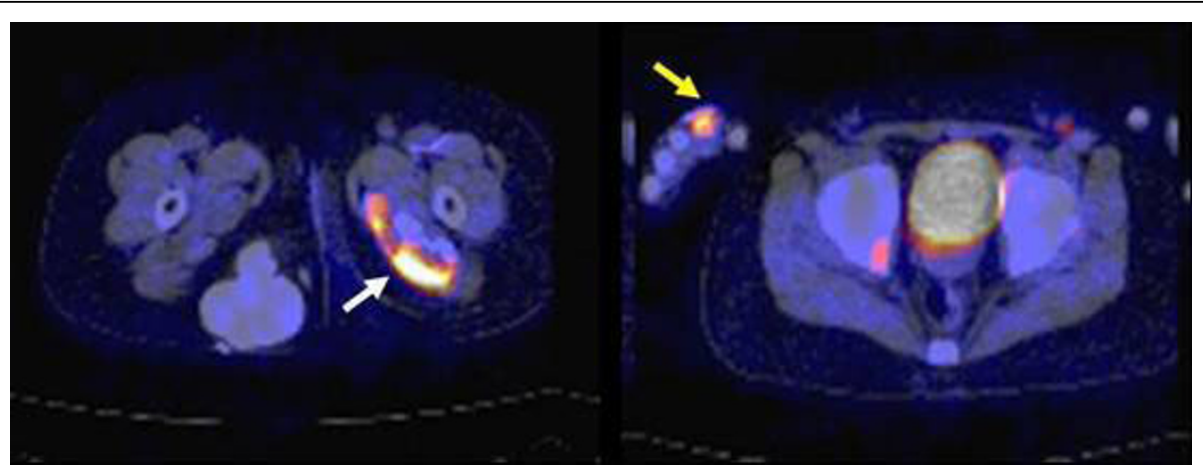

Figure 4 Findings of 18 FDG-PET/CT showing "inflammatory calcinosis"in August 2006. Subcutaneous and intramuscular calcification were recognized as in conventional plain $\mathrm{CT}$. Hot spots (white arrow) along with intramuscular calcification indicate inflammation. Even the small lesion of inflammation around a right digit (yellow arrow) can be seen clearly.

$3.08 \mathrm{mg} / \mathrm{dL}$. Recent examination by whole-body $18 \mathrm{~F}$ FDG-PET-CT over the 15 months of thalidomide treatment demonstrated fewer hot spots around the subcutaneous calcified lesions.

\section{Discussion}

Treatment with thalidomide produced a sustained major clinical improvement in a case of JDM with inflammatory calcinosis refractory to the conventional corticosteroids and immunosuppressants and even to etanercept.

The mechanism of the inflammatory calcinosis of JDM is still unclear. Pachman et al. speculated that calcification occurring at sites where it is undesirable, as opposed to physiologic calcification, is usually designated as "pathologic" or, when associated with cell death, as "dystrophic" in nature [12]. Scientifically, at least, as Table 1 shows, it has been shown that inflammation accompanied by calcinosis is characterized by multiple proinflammatory cytokinemia including TNF-alpha, IL-6, and IL-1beta. The level of IL10 in the calcium milk was also elevated. IL-10 is a cytokine with potent anti-inflammatory properties, which represses the expression of inflammatory cytokines such as TNF-alpha, IL- 6 and IL-1 by activated macrophages. This finding may indicate that in parallel with the

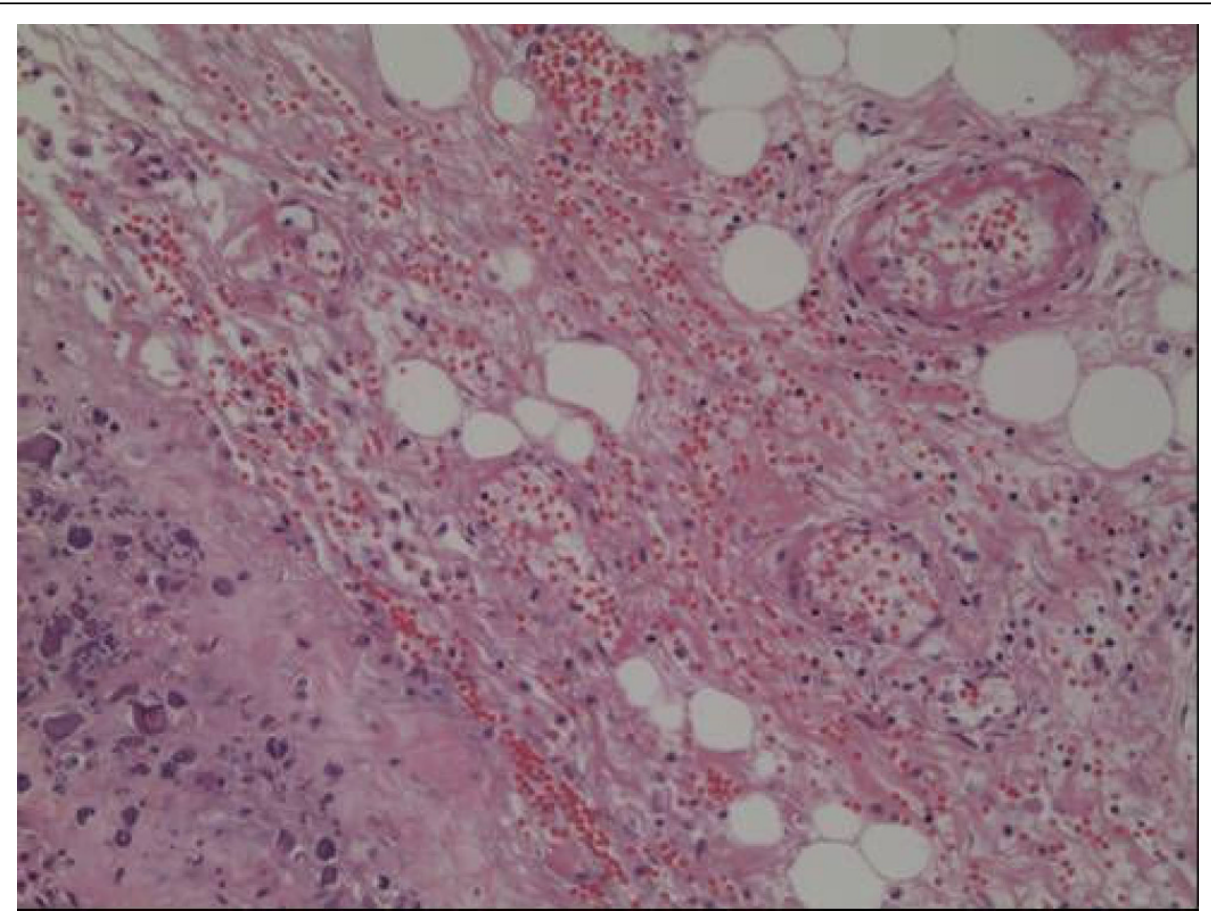

Figure 5 Light microscopy of calcium deposits with soft tissue obtained in the left thigh during surgery. Bordered with calcium plaques (arrow), fibrinoid vasculitis was observed with hemorrhage and degeneration of adipose cells. (H\&E stain, 20x). 
Table 1 Laboratory findings of the patient.

\begin{tabular}{|c|c|c|c|c|}
\hline & $\begin{array}{c}2001 \\
\begin{array}{c}\text { During inflammatory } \\
\text { calcinosis }\end{array} \\
\end{array}$ & $\begin{array}{l}2006 \\
\text { Before thalidomide } \\
\text { (inacitive phase) }\end{array}$ & 3 months & 12 months \\
\hline WBC $(\mu \mathrm{L})$ & 27,300 & 7,100 & 6,400 & 5,200 \\
\hline $\mathrm{Hb}(\mathrm{g} / \mathrm{dL})$ & 11.6 & 11.3 & 9.5 & 12.7 \\
\hline Platelets $\left(\times 10^{4} / \mu \mathrm{L}\right)$ & 24.7 & 24.6 & 35.7 & 35.7 \\
\hline $\mathrm{ESR}(\mathrm{mm} / \mathrm{h})$ & 27 & 17 & 3 & 4 \\
\hline FDP-E (ng/mL) & 225 & 237 & 95 & 85 \\
\hline AST (U/L) & 20 & & & \\
\hline ALT $(U / L)$ & 7 & & & \\
\hline $\mathrm{LDH}(\mathrm{U} / \mathrm{L})$ & 271 & & & \\
\hline CRP (mg/dL) & 21.0 & 0.2 & 0.1 & 0.4 \\
\hline Triglycerides (mg/dL) & nd & 251 & 74 & 93 \\
\hline Total cholesterol (mg/dL) & nd & 121 & 145 & 156 \\
\hline $\operatorname{lgG}(\mathrm{mg} / \mathrm{dL})$ & nd & 2,056 & 813 & 916 \\
\hline
\end{tabular}

The levels of FDP-E, IgG, and triglycerides were all elevated before thalidomide gradually reduced them to the normal range.

predicted activation of the immune response and tissue injury pathways caused by TNF-alpha, IL- 6 and IL-1, there is simultaneous activation of pathways for the counter-regulatory and the protective mechanisms that would balance and limit the ongoing inflammatory/immune responses.

The effect of infliximab in refractory calcinosis with juvenile dermatomyositis was reported previously [7]. The anti-TNF-alpha biologics such as infliximab and etanercept are designed specifically to target TNF-alpha. Unlike the mechanism of action of the biologics, thalidomide has complex immunomodulatory and antiinflammatory properties. It has been shown to downregulate the production of TNF-alpha and other proinflammatory cytokines, to inhibit the transcription factor nuclear factor kappa B (NF kappaB), and to downregulate cyclooxygenase $2[13,14]$. This might explain why thalidomide was more effective in the present case than etanercept. The calcified deposits contained the bone proteins osteopontin, osteonectin, and sialoprotein. Hydroxyapatite was the only mineral detected, but the tissue was distinct from bone, with an extremely high mineral content and an irregular distribution of minerals [12]. The same authors also reported that calcifications from JDM patients contained more osteonectin than is usually found in human bone. In vitro studies indicate that osteonectin can bind collagen and regulate angiogenesis, metalloproteinase expression, cell proliferation, and cell-matrix interactions [15].

Thalidomide is not only an immunomodulatory drug but also has anti-angiogenic effects [16]. It has been reported, for example, in myeloma, to suppress angiogenic factors such as vascular endothelial growth factor (VEGF), and inflammatory genes such as TNF-alpha and IL- $6[17,18]$. The anti-angiogenic effect may be a part of the thalidomide mechanism that reverses inflammatory calcinosis.

The pathological specimen showed fibrinoid vasculitis surrounding calcinosis. It is hard to explain whether the inflammatory calcinosis is due to muscle vasculitis because there was no muscle vasculitis where no calcinosis was present. Muscle vasculitis arising from JDM should be symmetrical. We prefer to surmise that fibrinoid vasculitis was followed by the calcinosis universalis itself. Besides, no report of a direct relationship between vasculitis and calcinosis universalis has appeared in the literature.

The findings of 18F-FDG-PET-CT after thalidomide treatment included fewer hot spots showing local inflammation around subcutaneous calcified lesions. This suggested that the subcutaneous pooling of calcium milk may be the cause of proinflammatory cytokinemia and subsequent "inflammatory calcinosis" in JDM, and the suppression of NF kappaB activation by thalidomide is likely to be beneficial for inhibiting the systemic spread of inflammation.

\section{Consent}

Written informed consent was obtained from the patient for publication of this case report and any accompanying images. A copy of the written consent is available for review by the Editor in Chief of this journal. 


\section{Acknowledgements}

The authors thank Mr. C.W.P. Reynolds for his careful linguistic help with this manuscript. The authors declare no competing financial interests.

\section{Author details}

'Department of Pediatrics, Yokohama City University, 3-9 Fukuura Kanazawaku, Yokohama 236-0004, Japan. ²Department of Pathology, Yokohama City University, 3-9 Fukuura, Kanazawaku, Yokohama 236-0004, Japan.

\section{Authors' contributions}

TM drafted the manuscript and participated in its design. SF, RO, and TI participated in drafting of the manuscript and participated in its design. $Y$ participated in the drafting of the manuscript and supplied the pathological image used for the manuscript. SY conceived of the case report, participated in drafting the manuscript and gave final approval for the version to be submitted for publication.

\section{Competing interests}

The authors declare that they have no competing interests.

\section{Received: 5 March 2009}

Accepted: 4 February 2010 Published: 4 February 2010

\section{References}

1. Cassidy JT, Lindsley CB: Juvenile Dermatomyositis. Textbook of Pediatric Rheumatology Philadelphia: Elsevier SaunderCassidy JT, Petty RE , 5 2005, 407-41.

2. Huber AM, Lang B, LeBlanc CM, Birdi N, Bolaria RK, Malleson P, MacNeil I, Momy JA, Avery G, Feldman BM: Medium- and long-term functional outcomes in a multicenter cohort of children with juvenile dermatomyositis. Arthritis Rheum 2000, 43:541-9.

3. Fisler RE, Liang MG, Fuhlbrigge RC, Yalcindag A, Sundel RP: Aggressive management of juvenile dermatomyositis results in improved outcome and decreased incidence of calcinosis. J Am Acad Dermatol 2002, 47:505-11

4. Mukamel M, Horev G, Mimouni M: New insight into calcinosis of juvenile dermatomyositis: a study of composition and treatment. J Pediatr 2001, 138:763-6.

5. Pachman LM, Liotta-Davis MR, Hong DK, Kinsella TR, Mendez EP, Kinder JM, Chen EH: TNFalpha-308A allele in juvenile dermatomyositis: association with increased production of tumor necrosis factor alpha, disease duration, and pathologic calcifications. Arthritis Rheum 2000, 43:2368-77.

6. Pachman LM, Abbott K, Sinacore JM, Amoruso L, Dyer A, Lipton R, Ilowite N, Hom C, Cawkwell G, White A, Rivas-Chacon R, Kimura Y, Ray L, Ramsey-Goldman R: Duration of illness is an important variable for untreated children with juvenile dermatomyositis. J Pediatr 2006, 148:247-53.

7. Riley P, MacCann LJ, Maillard SM, Woo P, Murray KJ, Pilkington CA: Effectiveness of infliximab in the treatment of refractory juvenile dermatomyositis with calcinosis. Rheumatology 2008, 47:877-80.

8. Yasui K, Uchida N, Akazawa Y, Nakamura S, Minami I, Amano Y, Yamazaki T: Thalidomide for treatment of intestinal involvement of juvenile-onset Behçet disease. Inflamm Bowel Dis 2008, 14:396-400.

9. García-Carrasco M, Fuentes-Alexandro S, Escárcega RO, Rojas-Rodriguez J, Escobar LE: Efficacy of thalidomide in systemic onset juvenile rheumatoid arthritis. Joint Bone Spine 2007, 74:500-3.

10. Rowland TL, McHugh SM, Deighton J, Dearman RJ, Ewan PW, Kimber I: Differential regulation by thalidomide and dexamethasone of cytokine expression in human peripheral blood mononuclear cells. Immunopharmacology 1998, 40:11-20.

11. Calabrese L, Fleischer AB: Thalidomide: current and potential clinical applications. Am J Med 2000, 108:487-95.

12. Pachman LM, Veis A, Stock $S$, Abbott $K$, Vicari F, Patel P, Giczewski $D$, Webb C, Spevak L, Boskey AL: Composition of Calcifications in children with juvenile dermatomyositis association with chronic cutaneous inflammation. Arthritis Rheum 2006, 54:3345-3350.

13. Sampaio EP, Sarno EN, Galilly R, Cohn ZA, Kaplan G: Thalidomide selectively inhibits tumor necrosis factor alpha production by stimulated human monocytes. J Exp Med 1991, 173:699-703.
14. Gordon JN, Goggin PM: Thalidomide and its derivatives: emerging from the wilderness. Postgrad Med J 2003, 79:127-32.

15. Gerber HP, Vu TH, Ryan AM, Kowalski J, Werb Z, Ferrara N: VEGF couples hypertrophic cartilage remodeling, ossification and angiogenesis during endochondral bone formation. Nat Med 1999, 5:617-8.

16. Bauer JA, Morrison BH, Grane RW, Jacobs BS, Borden EC, Lindner DJ: IFNalpha2b and thalidomide synergistically inhibit tumor-induced angiogenesis. J Interferon Cytokine Res 2003, 23:3-10.

17. Raje N, Anderson KC: Thalidomide and immunomodulatory drugs as cancer therapy. Curr Opin Oncol 2002, 14:635-40.

18. Meierhofer C, Dunzendorfer S, Wiedermann CJ: Theoretical basis for the activity of thalidomide. Biodrugs 2001, 15:681-703.

doi:10.1186/1546-0096-8-6

Cite this article as: Miyamae et al:: Efficacy of thalidomide in a girl with inflammatory calcinosis, a severe complication of juvenile dermatomyositis. Pediatric Rheumatology 2010 8:6.

\section{Submit your next manuscript to BioMed Central and take full advantage of:}

- Convenient online submission

- Thorough peer review

- No space constraints or color figure charges

- Immediate publication on acceptance

- Inclusion in PubMed, CAS, Scopus and Google Scholar

- Research which is freely available for redistribution
C Biomed Central 